MATEC Web of Conferences 33, 01002 (2015)

DOI: $10.1051 /$ matecconf/ 20153301002

(C) Owned by the authors, published by EDP Sciences, 2015

\title{
Highly mobile interfaces in shape memory alloys
}

\author{
Hanuš Seiner $^{1}$ \\ ${ }^{1}$ Institute of Thermomechanics, Academy of Sciences of the Czech Republic, 18200 Prague, Czech Republic
}

\begin{abstract}
Macro-twin interfaces in single crystals of $10 \mathrm{M}$ modulated Ni-Mn-Ga martensite have recently attracted a lot of attention due to the extraordinarily low twinning stress required to set them into motion; depending on the particular twinning mode, this stress can range between 0.05 and $1 \mathrm{MPa}$, and can be either strongly temperature dependent, or nearly temperature independent. The understanding to these effects is still not satisfactory, mainly due to the high complexity of these interfaces at the micro-scale (higher-order lamination) as well as at the atomistic scale (modulations of martensite). This paper brings a brief review of the recent experimental and theoretical achievements related to these highly mobile interfaces. The uniqueness of the behavior of $10 \mathrm{M}$ martensite is shown by its comparison with other shape memory alloys with relatively low twinning stresses; then, this behavior is discussed in terms of its temperature dependence, strain rate dependence and the effect of the micromorphology of the interfaces.
\end{abstract}

\section{Introduction}

For several applications of shape memory alloys (SMAs), the key parameter is the twinning stress, i.e. the stress required for a twinning plane to set into a steady motion. Especially for ferromagnetic shape memory alloys (FSMAs) exhibiting the magnetically induced reorientation (MIR) effect [1-3] and intended for applications as magnetic-field driven actuators, the decrease in the twinning stress directly implies a decrease of the magnetic field necessary for the actuation.

While the twinning stress in conventional SMAs, such as in $\mathrm{Ni}-\mathrm{Ti}$, is mostly above the level of $20 \mathrm{MPa}$ [4], extraordinarily low twinning stress has been observed for the $10 \mathrm{M}$ modulated martensite of the NiMnGa FSMA. For single crystals of this alloy, as low twinning stress as $0.05 \mathrm{MPa}$ has been observed [5-7]; simultaneously, higher but still relatively low twinning stresses of about 0.7-1 MPa have been reported for the same alloy by other authors $[8,9]$. This discrepancy has been sufficiently explained by Sozinov et al. [10] and later in more details by Straka et al. [11] by showing that the interfaces with the highest mobility are Type 2 twins, while those with the approximately ten times higher twinning stress are Type 1 twins, following the notation of the twinning systems from [12]. To distinguish between these two types of twins from the crystallographic point of view, it is necessary to assume the unit cell of $10 \mathrm{M}$ martensite as monoclinic, not tetragonal $[13,14]$; then the Type 1 interface is a $<110>$ lattice plane of the $10 \mathrm{M}$ structure, while Type 2 twinning plane is a general non-rational plane, inclined from the nearest $\langle 110\rangle$ plane by approximately $4^{\circ}$. Nevertheless, both these twinning systems correspond to a rotation of the $c$-axis, i.e. the axis of easy magnetization, by $90^{\circ}$ and can be, thus, termed as $a-c$ twins. Hence, these twinning systems are inducible by external magnetic field and contributing to the MIR effect.

The difference between the Type 1 and Type 2 twinning stresses, as well as the low value for Type 2 itself has been a subject of intense experimental and theoretical research during the last few years. In this paper, a brief summary of this research is given, with the focus laid on the attempts to explain these phenomena. The presented summary is far from comprehensive, but aims to cover the main directions followed by the current research in the field, and to show that despite of a large number of experimental and theoretical findings available in the literature, some part of the understanding to the behavior of mobile interfaces in Ni-Mn-Ga is still lacking.

\section{Comparison with other SMAs}

Although the twinning stresses below $0.1 \mathrm{MPa}$ (i.e. of Type 2) have not been observed yet for any other material than $10 \mathrm{M}$ modulated NiMnGa, the twinning stresses of the order of $1 \mathrm{MPa}$ (i.e. of Type 1), is not that rare. The other possible modulated martensitic structure of NiMnGa, $14 \mathrm{M}$, exhibits also relatively low twinning stress of $1 \mathrm{MPa}$ (i.e reorientation under $2 \mathrm{MPa}$ of compressive stress), as observed by Sozinov et al. [15].

For non-modulated (NM) martensite, the twinning stresses are much higher (above $50 \mathrm{MPa}$ [16]); however, for the $\mathrm{NM}$ martensite of the $\mathrm{Ni}_{46} \mathrm{Mn}_{24} \mathrm{Ga}_{22} \mathrm{Co}_{3} \mathrm{Cu}_{3}$ alloy, reorientation under a $1.2 \mathrm{MPa}$ compressive loads was observed [17]. This indicates that the high mobility of the interfaces may not be directly related to the modulations 
or to the crystal structure. This is also in agreement with the fact that while a Ni-Mn-Ga-Co alloy ( 4.9 at.\% of Co) with very similar structure and lattice parameters as $14 \mathrm{M}$ Ni-Mn-Ga exhibits a conventionally high twinning stress

Also the Heusler-type atomic order in Ni-Mn-Ga is probably not the decisive parameter. Kakeshita et al. [20] estimated the twinning stress of $0.6-1.2 \mathrm{MPa}$ for a fully disordered $\mathrm{Fe}-31.2 \mathrm{Pd}$ alloy from magnetic measurements.

From the non-magnetic shape memory alloys, the lowest documented twinning stress was observed for the Compound twins of the $2 \mathrm{H}$ martensite of the $\mathrm{Cu}-\mathrm{Al}-\mathrm{Ni}$ : reorientation under a $0.7 \mathrm{MPa}$ shear stress was reported by Novák et al.[21]. It is interesting to point out that the Compound twinning system in $\mathrm{Cu}-\mathrm{Al}-\mathrm{Ni}$ is highly symmetric, with both the shearing vector and the twinning plane being rational (i.e. the shearing vector is the lattice vector and the twinning plane is the lattice plane of $\mathrm{Cu}-\mathrm{Al}-\mathrm{Ni}$ ), while the highly mobile interfaces in $\mathrm{Ni}-\mathrm{Mn}-\mathrm{Ga}$ have either non-rational shearing vectors (Type 1) or non-rational twinning plane (Type 2). Nevertheless, the highly mobile Compound twins in $\mathrm{Cu}$ Al-Ni have not caught comparable attention to those in $\mathrm{Ni}-\mathrm{Mn}-\mathrm{Ga}$, mostly because of the non-magnetic behavior of $\mathrm{Cu}-\mathrm{Al}-\mathrm{Ni}$ and, thus, of its lower applicability potential. In summary, the comparison of $10 \mathrm{M} \mathrm{Ni-Mn-Ga} \mathrm{with}$ other SMAs does not bring any clear explanation neither of the high mobility of Type 1 and Type 2 interfaces, nor of the difference between them.

\section{Temperature dependence and thermal activation}

The twinning stress in SMAs is typically strongly temperature-dependent. For NiTi, for example, the twinning stress is the lowest in the vicinity of the MS temperature and increases steeply upon cooling [4]. This increase of the twinning stress at low temperatures may be understood as a result of the thermally-activated character of the quasi-static twin boundary propagation mechanism: if the main resistance of the twin boundary against the motion originates from pinning of the boundary on defects and crystal imperfections, activation by thermal fluctuations is needed to release the interface from local energy minima. Straka et al. [22] conducted an extensive experimental study of a set of alloys $\mathrm{Ni}_{50} \mathrm{Mn}_{25+x} \mathrm{Ga}_{25-x}$ (at.\%) with $x$ ranging from 3 to 4 . For all studied alloys, the Type 1 interfaces exhibited a fast increase of the twinning stress with the temperature decreasing from AS, while the twinning stress for Type 2 was reported as temperature independent for all alloys. This study was later extended to cryogenic temperatures by Straka et al. [23] and Heczko et al. [24], showing that for those alloys, for which the $10 \mathrm{M}$ martensite undergoes a further transition to $14 \mathrm{M}$, the twinning stress for Type 2 increases sharply in the vicinity of the intermartensitic transition temperature. For alloys without the intermartensitic transition, the high mobility of Type 2 interfaces and the consequent MIR was observed down to $1.7 \mathrm{~K}$ [24].
[18] (reorientation under $25 \mathrm{MPa}$ ), the $14 \mathrm{M}$ martensite of Ni-Fe-Ga-Co alloy has a low twinning stress of approximately $1 \mathrm{MPa}$ [19].

These results suggest that while the thermal activation may play an important role for Type 1 interfaces, the character of motion of the Type 2 interfaces is rather athermal. This assumption is further supported by the fact that the stress-strain curves for crystals with Type 1 interfaces show more pronounced jerkiness [10], which may correlate with stronger pinning of the Type 1 interface on the defects. Faran and Shilo [25-29] studied this jerkiness in more details, and showed that fine oscillation of the stress-strain response may correspond to pinning on obstacles with a characteristic spacing of approximately 10-50 $\mu \mathrm{m}$; see also [30] for the analysis of this jerkiness by acoustic emission measurements. However, these fine oscillations were reported by Faran and Shilo [27] for both Type 1 and Type 2 interfaces (for the latter, this effect was also confirmed by observations by Barabash et al.[31]), and so the relation between these 'obstacles' and the difference in thermal dependences of Type 1 and Type 2 twinning stresses becomes questionable. The fact that mechanisms of motion of the Type 1 and Type 2 interfaces are similar, at least from the point of view of thermal activation, was also confirmed be the recent acoustic emission measurements [32].

Heczko et al. [33], nevertheless, point out a clear theoretical reason why the thermal activation should play a more important role for the Type 1 interface (see also [34] for a more general discussion). The Type 1 twinning plane is a $<110>$ lattice plane of the $10 \mathrm{M}$ structure; as such, it can be up to atomically sharp, and so it can be assumed as significantly shaper than the non-rational Type 2 twinning plane. The sharper interface is then necessarily more sensitive both to the Peierls landscape and to pinning on defects or other obstacles. However, the $10 \mathrm{M}$ unit cell is very complex, especially in the case of incommensurate $10 \mathrm{M}$ modulations [14], and so the effective $<110>$ plane has similarly general location with respect to the atomic positions as the non-rational Type 2 interface. Moreover, as seen from the example of Compound twins in $\mathrm{Cu}-\mathrm{Al}-\mathrm{Ni}$ [21], the high mobility is possible also for very sharp, highly symmetric twin interfaces.

\section{Behavior under dynamic loads}

The extraordinary low twinning stress of the Type 1 and Type 2 interfaces observed under quasi-static loadings affects also significantly the behavior of Ni-Mn-Ga single crystals under higher strain rates. For pulse-like magnetic field loads, a detailed study of mobility of Type 1 and Type 2 interfaces can be found in the above mentioned papers by Faran and Shilo [25-29]. The main conclusion from this study is that the dynamic behavior of the interfaces exhibits some kind of bimodal behavior: for low driving forces, the interfaces move by a nucleationand-growth mechanism, which involves thermal activation. Above some critical level of the driving force, however, this mechanism is overridden by fast athermal 
motion of twinning dislocations. This critical level of the driving force was found to be significantly smaller for Type 2 than for Type 1; this, again, somehow indicates that the Type 2 interface is less affected by the Peierls landscape or by interaction with defects.

Other interesting results were obtained for periodic (vibrational) loadings. Pascan et al. [35] studied the energy dissipation in Ni-Mn-Ga crystals with highly mobile interfaces in a frequency range up to $300 \mathrm{~Hz}$. They observed that while in the quasi-static tests the main source of the dissipated energy are the Type 1 interfaces, the dissipation from Type 2 interfaces becomes dominant in the dynamic case. This may indicate that the motion of the Type 2 interfaces can be described by means relaxation mechanics, in which the vibrations induce some energy dissipation even in the high-frequency limit [36].

Furthermore, Techapiesancharoenkij et al. [37] showed that the acoustic vibrations at even higher frequencies (up to $5 \mathrm{kHz}$ ) have a significant impact on the mobile interfaces, most probably Type 1 twins in this case. In particular, a decrease in the twinning stress by from 0.7 to $0.45 \mathrm{MPa}$ due to the assistance of the vibrations was observed. The amplitude of the vibrations was comparable to the twinning stress for the interfaces, and so the resulting applied stress was a superposition of the quasi-static and dynamic components. The highamplitude ultrasound was also shown to be able to actuate the mobile interfaces in Ni-Mn-Ga single crystals by Chambers [38] and Simon [39] (see also the references therein).

Recent ultrasonic experiments by Sedlák et al. [40] show that the Type 2 interfaces are able to interact also with low-amplitude vibrations at as high frequencies as $100 \mathrm{kHz}$. Even in this frequency range and for displacement amplitudes of few nanometers, the single crystals with Type 2 interfaces exhibit strongly dissipative, non-linear vibrational response, revealing hysteretic dynamic behavior of the twins.

\section{Finer structure of the mobile interface}

Already the $\mu \mathrm{X}$-ray measurements in [11] showed that the mobile interfaces are not simple twinning planes, but are rather complex interfaces between martensitic laminates. Due to the monoclinic symmetry of the lattice, the $10 \mathrm{M}$ martensite is able to form the modulation twins ((100)-Compound twins) and the $a-b$ twins ((110)-Compound twins), which are both such types of twins that the orientation of the $c$-axis does not change over the twinning plane. Fine laminates of these types of twins were found in the vicinity of the highly mobile interfaces also by Straka et al. [11], Heczko et al. [33] and Chulist et al. [41]; as a result, the mobile interface is then a macro-twin interfaces between these laminates. The micro-morphology of such interfaces was shown to have a multi-scale hierarchical character by Barabash et al. [42] for the case of $10 \mathrm{M}$ martensite of $\mathrm{NiMnGaFeCu}$. Typically, this complex structure is not discussed in the theoretical models of motion, including those of the mobility of the twins by Faran and Shilo [25-29] as well as continuum mechanics or phase field models of MIR $[43,44]$. Nevertheless, the theoretical twinning stress calculated for the symmetric Type 1 interface as for a perfect twinning plane by first-principles atomistic simulations [45] (3.5 MPa) is significantly higher than the experimentally observed values $(0.5-1 \mathrm{MPa})$; this discrepancy may indicate that the finer structure may destabilize the interface and affect the twinning stress.

The EBSD analysis by Chulist et al. [41,46] also revealed that there can exist interfaces composed of segments of Type 1 and Type 2 twins (see also [33] for a theoretical compatibility analysis of such interfaces and for the corresponding optical micrographs). The critical twinning stress for such an interface is then between the twinning stresses for Type 1 and Type 2 .

Another possible effect of the complex micromorphology was discussed by a microstructural model [47] formulated within the frame of continuum mechanics. The model was formulated at three different length-scales: the effect of the modulation laminates was considered at a milimeter-scale, the effect of the $a-b$ at the micrometer-scale, and at the nano-scale, it was assumed that the the motion of the interface can be affected by an interaction with the modulated structure. At all these spatial scales, the model predicted a possibility for pinning of the interface at locally compatible states for Type 1 interfaces but not for Type 2 interfaces. However, it is hard to decide whether such pinning is in any relation with the experiments and at which of the spatial scales it can be expected. The characteristic spacing between the obstacles $(\sim 10-50 \mu \mathrm{m})$ resulting from the analysis of mobility given in [25-29] seem to relate to the characteristic thickness of the $a-b$ lamina observed by Chulist et al.[41]. However, the differences between the Type 1 and Type 2 interfaces were observed also for alloys with $a \approx b$ [48], which proves that such a pining is not a dominant mechanism.

At the nano-scale, the fine structure of the Type 1 and Type 2 interfaces was observed by HRTEM by Matsuda et al. [49]. The results confirmed the assumption that the Type 2 interfaces are broader: while the periodic contrast from the structural modulations was clearly visible directly at the Type 1 interface, the contrast around the Type 2 interface was blurry and the interface itself appeared to be largely and randomly curved. This observation indicates that the nano-scale compatibility conditions between the modulated structures may affect strongly the character of the interface, and, possibly, also its mobility. However, there are not available any theoretical tools for modelling the nano-scale morphology of such interfaces; the currently developed continuum models based of multi-well Fourier multipliers [50] that aim to open such a possibility are still at their infancy. According to $\mathrm{Li}$ et al. [51] the structure of the interface at this scale may be significantly affected by the commensurateness or incommensurateness of the $10 \mathrm{M}$ modulated structure.

\section{Concluding Remarks}


There are several other directions of research related to high mobility of Type 1 and Type 2 twins in Ni-Mn-Ga that are not addressed in this paper. In particular, there have been a lot of development in the smart applications of Ni-Mn-Ga single crystals in the past few years (e.g. [52-54]). Also the works concerned with appearance of Type 1 and Type 2 interfaces in Ni-Mn-Ga thin films (e.g. $[55,56])$, those discussing the role of these interfaces for the nucleation of martensite in austenite (e.g. $[57,58]$ ), or those documenting the effect of the motion of these interfaces onto the microstructure of magnetic domains [59] fall beyond the scope of this review. On the other hand, this review naturally overlaps with other general papers summarizing the properties of the highly mobile interfaces and their role for the magnetic shape memory effect $[60,61]$, although these papers are written from a slightly different point of view.

\section{Acknowledgement}

Many issues addressed in this review were intensively discussed by the author with O. Heczko (ASCR Prague), L. Straka (Aalto University), D. Shilo (Technion Haifa), S. Stupkiewicz (IPPT Warsaw), S. Faehler (IFW Dresden), C. Melcher (RWTH Aachen), and many of their coworkers.

The financial support from Czech Science Foundation (14-15264S) is also acknowledged.

\section{References}

1. K. Ullakko, J.K. Huang, C. Kanter, R.C. O’Handley, V.V. Kokorin, Appl. Phys. Lett. 69, 1966 (1996)

2. O. Heczko, A. Sozinov, and K. Ullakko, IEEE Trans. Magn. 36, 3266 (2000)

3. O. Söderberg, Y. Ge, A. Sozinov, S.-P. Hannula, and V. K. Lindroos:, in K. H. J. Buschow (ed.), Handbook of Magnetic Materials (Elsevier Science, Amsterdam, 2006), Vol. 16, pp. 1-39

4. K. Otsuka, X. Ren, Prog. Mater. Sci. 50, 511 (2005)

5. L. Straka, H. Hänninen, A. Soroka, A. Sozinov, J. Phys.: Conf. Ser. 303, 012079 (2011)

6. L. Straka, N. Lanska, K. Ullakko, A. Sozinov, Appl. Phys. Lett. 96, 131903 (2010)

7. L. Straka, H. Hänninen, O. Heczko, Appl. Phys. Lett. 98, 141902 (2011)

8. C. Bechtold, A. Gerber, M. Wuttig, E. Quandt, Scripta Mater., 58, 1022 (2008)

9. L. Straka, V. Novák, M. Landa, O. Heczko, Mater. Sci. Eng. A, 374, 263 (2004)

10. A. Sozinov, N. Lanska, A. Soroka, L. Straka, Appl. Phys. Lett. 99, 124103 (2011)

11. L. Straka, O. Heczko, H. Seiner, N. Lanska, J. Drahokoupil et al., Acta Mater. 59, 7450 (2011)

12. K. Bhattacharya, Microstructure of martensite (Oxford University Press, New York, 2003)

13. N. Lanska, O. Söderberg, A. Sozinov, Y. Ge, K. Ullakko, V.K. Lindroos, J. Appl. Phys. 95, 8074 (2004)

14. L. Righi, F. Albertini, L. Pareti, A. Paoluzi, G. Calestani, Acta Mater. 55, 5237 (2007)
15. A. Sozinov, A.A. Likhachev, N. Lanska, K. Ullakko, V.K. Lindroos, Proc. SPIE 4699, 195 (2002)

16. A. Sozinov, A. A. Likhachev, N. Lanska, O. Söderberg, K. Koho, K. Ullakko, V. K. Lindroos, J. Phys. IV, France 115, 121 (2004)

17. A. Sozinov, N. Lanska, A. Soroka, and W. Zou, Appl. Phys. Lett. 102, 021902 (2013)

18. K. Rolfs, M. Chmielus, R.C. Wimpory, A. Mecklenburg, P. Müllner, R. Schneider, Acta Mater. 58, 2646 (2010)

19. H. Morito, K. Oikawa, A. Fujita, K. Fukamichi, R. Kainuma, K. Ishida, Scripta Mater. 53, 1237 (2005)

20. T. Kakeshita, T. Fukuda, T. Takeuchi, Mater. Sci. Eng. A 438-440, 12 (2006)

21. V. Novák, P. Šittner, S. Ignácová, and T. Černoch, Mater. Sci. Eng. A, 438-440, 755 (2006)

22. L. Straka, A. Soroka, H. Seiner, H. Hänninen, A. Sozinov, Scripta Mater. 67, 25 (2012)

23. L. Straka, A. Sozinov, J. Drahokoupil, V. Kopecký, H. Hänninen, O. Heczko, J. Appl. Phys., 114, 063504 (2013)

24. O. Heczko, V. Kopecký, A. Sozinov, L. Straka, Appl. Phys. Lett. 103, 072405 (2013)

25. E. Faran, D. Shilo, J. Mech. Phys. Solids 59, 975 (2011)

26. E. Faran, D. Shilo, Appl. Phys. Lett. 100, 151901 (2012)

27. E. Faran, D. Shilo, J. Mech. Phys. Solids 61, 726 (2013)

28. E. Faran, D. Shilo, Mater. Sci. Technol. 30, 1545 (2014)

29. E. Faran, D. Shilo, Shape Memory Superelast. 1, 180 (2015)

30. E. Faran, E. K. H. Salje, D. Shilo, Appl. Phys. Letters 107, 071902 (2015).

31. R. I. Barabash, C. Kirchlechner, O. Robach, O. Ulrich, J.-S. Micha, A. Sozinov, O. M. Barabash, Appl. Phys. Lett. 103, 021909 (2013)

32. O. Perevertov, V. Kopecký, H. Seiner, M. Landa, O. Heczko, ESOMAT2015, Antwerp, Belgium, poster presentation

33. O. Heczko, L. Straka, H. Seiner, Acta Mater. 61, 622 (2013).

34. E.K.H. Salje, Phase Trans. 83, 657 (2010)

35. O.-Z. Pascan, Y.J. He, Z. Moumni, and W.H. Zhang, Scripta Mater. 104, 71 (2015)

36. A.S. Nowick, B.S. Berry, Anelastic relaxation in crystalline solids, (Academic Press, New York, 1972)

37. R. Techapiesancharoenkij, J. Simon, D. Bono, S. M. Allen, R. C. O'Handley, J. Appl. Phys. 104, 033907 (2008)

38. J. M. Chambers, Design and Characterization of Acoustic Pulse Shape Memory Alloy Actuators, Ph.D. Thesis, (MIT, Cambridge, 2005)

39. J.M. Simon, Transverse Acoustic Actuation of $\mathrm{Ni}$ Mn-Ga single crystals, Ph.D. Thesis, (MIT, Cambridge, 2007)

40. P. Sedlák, H. Seiner, V. Kopecký, O. Heczko, M. Landa, ESOMAT2015, Antwerp, Belgium, poster presentation 
41. R. Chulist, L. Straka, N. Lanska, A. Soroka, A. Sozinov, W. Skrotzki, Acta Mater. 61, 1913 (2013)

42. R. I. Barabash, O. M. Barabash, D. Popov, G. Shen, C. Park and W. Yang, Acta Mater. 87, 344 (2015)

43. X. Chen, Z. Moumni, Y. He, W. Zhang, J. Mech. Phys. Solids 64, 249 (2014)

44. Q. Peng, Y.J. He, Z. Moumni, Acta Mater. 88, 13 (2015)

45. J. Wang, H. Sehitoglu, Acta Mater. 61, 6790 (2013)

46. R. Chulist, L. Straka, A. Sozinov, A., et al. 2013 TMS Annual Meeting, 959 (2013)

47. H. Seiner, L. Straka, O. Heczko, J. Mech. Phys. Solids 64, 198 (2014)

48. L. Straka, J. Drahokoupil, O. Pacherová, K. Fabiánová, V. Kopecký, H. Seiner, H. Hänninen, O. Heczko, Smart. Mater. Struct. (submitted)

49. M. Matsuda, Y. Yoshihiro, H. Kimiaki, T. Hara, M. Nishida, Mater. Trans. 53, 902 (2012)

50. B. Benešová, M. Frost, M. Kampshulte, C. Melcher, H. Seiner, in: G. Dolzman (ed.), $14^{\text {th }} G A M M$ Seminar on Microstructures (Universität Regensburg, Regensburg, 2009) p.22
51. Z. Li, Y. Zhang, C. Esling, X. Zhao, L. Zuo, Acta Mater. 60, 6982 (2012)

52. O.Y. Kanner, D. Shilo, J. Sheng, R.D. James, Y. Ganor, Smart Mater. Struct. 22, 085030 (2013)

53. D. Kellis, A. Smith, K. Ullakko, P. Müllner, J. Cryst. Growth 359, 64 (2012)

54. J. Feuchtwanger, J. Aurrekoetxea, J. Zurbitu, et al., Mater. Trans. 55, 629 (2014)

55. A. Backen, S.R. Yeduru, A. Diestel, A., et al., Adv. Eng. Mater. 14, 696 (2012)

56. A. Diestel, V. Neu, A. Backen, L. Schultz, S. Fähler, J. Phys. Condens Matter 25, 266002 (2013)

57. S. Fähler, Interfaces in Multiferroic Magnetic Shape Memory Alloys, Habilitation thesis, (TU Dresden, 2013)

58. S. Fähler, ESOMAT2015, Antwerp, Belgium, invited talk.

59. V. Kopecký, L. Fekete, K. Jurek, J. Kopeček, L. Straka, H. Seiner, O. Heczko, IEEE Trans. Magn. (in press)

60. O. Heczko, IEEE Trans. Magn. 50, 6971350 (2014)

61. O. Heczko, Mater. Sci. Technol. 30, 1559 (2014) 
